Fifth International Conference on Sustainable Construction Materials and

Technologies. http://www.claisse.info/Proceedings.htm

\title{
EVALUATION OF SALT RESISTANCE OF CONCRETE COMBINED WITH CHLORIDE-ION IMMOBILIZER AND EXPANSIVE ADDITIVE
}

\author{
Shinya Ito ${ }^{1}$, Akihiro Hori ${ }^{2}$, Takeshi Iyoda ${ }^{3}$ \\ 1 Denka Company Limited. 2209, Omi, Itoigawa-city, Niigata 949-0393, Japan, \\ shinya-ito@denka.co.jp \\ 2 Denka Company Limited. 2209, Omi, Itoigawa-city, Niigata 949-0393, Japan, \\ akihiro-hori@denka.co.jp \\ 3 SHIBAURA INSTITUTE OF TECHNOLOGY. 3-7-5, Toyosu, Koto-ku, Tokyo \\ 135-8548, Japan, iyoda@ sic.shibaura-it.ac.jp
}

\begin{abstract}
Physical properties and salt resistance of concrete prepared with a chloride-ion immobilization material $\left(2 \mathrm{CaO} \cdot \mathrm{Al}_{2} \mathrm{O}_{3}\right)$ and expansive additive were examined. Immersion and unsteady-state electrophoresis tests confirmed that chloride-ion penetration of the concrete was suppressed using the chloride-ion immobilization material. The same behavior was confirmed in combination with the expansive additive. When the chloride-ion immobilization material and expansive additive were used in combination, there was no effect on salt resistance if the expansion strain was within the correct range. In contrast, in concrete using the chloride-ion immobilization material alone, the chloride-ion penetration behavior differed for salt-water immersion and unsteady-state electrophoresis tests.
\end{abstract}

Keywords: Salt resistance, Chloride-ion immobilization material, Expansive additive 


\section{INTRODUCTION}

In cold climates, severe salt damage and deterioration of concrete structures is caused by spraying of anti-freezing agents in winter. Salt damage occurs when soluble chloride ions penetrate into the concrete and cause corrosion of reinforcing rebar. In recent years, calcium aluminate, which immobilizes soluble chloride ions and renders them harmless, has been developed and many research results have been reported. Morioka (2005) found that $\mathrm{CaO} \cdot 2 \mathrm{Al}_{2} \mathrm{O}_{3}$ (hereinafter referred to as $\mathrm{CA}_{2}$ ), a calcium aluminate, is an effective additive to mitigate salt damage in Portland cement. $\mathrm{CA}_{2}$ reacts with cement hydrate $\mathrm{Ca}(\mathrm{OH})_{2}(\mathrm{CH})$, as shown in Equation 1, to produce hydrocalumite ( $\mathrm{HC}$ ). Equation 2 shows that $\mathrm{HC}$ chemically immobilizes the chloride ion as Friedel's salt and thereby decreases the soluble chloride ion concentration.

$$
\begin{aligned}
& 7 \mathrm{Ca}(\mathrm{OH})_{2}+\mathrm{CaO} \cdot 2 \mathrm{Al}_{2} \mathrm{O}_{3}+19 \mathrm{H}_{2} \mathrm{O} \rightarrow 2\left(3 \mathrm{CaO} \cdot \mathrm{Al}_{2} \mathrm{O}_{3} \cdot \mathrm{Ca}(\mathrm{OH})_{2} \cdot 12 \mathrm{H}_{2} \mathrm{O}\right) \\
& 3 \mathrm{CaO} \cdot \mathrm{Al}_{2} \mathrm{O}_{3} \cdot \mathrm{Ca}(\mathrm{OH})_{2} \cdot 12 \mathrm{H}_{2} \mathrm{O}+2 \mathrm{Cl}^{-} \rightarrow 3 \mathrm{CaO} \cdot \mathrm{Al}_{2} \mathrm{O}_{3} \cdot \mathrm{CaCl}_{2} \cdot 11 \mathrm{H}_{2} \mathrm{O}+2 \mathrm{OH}^{-}
\end{aligned}
$$

$\mathrm{CH}$ is consumed by Reaction 2, so it is possible to suppress the leaching of $\mathrm{Ca}$ and the accompanying porosity when chloride ions are supplied (Tabara, 2010; 2011). It is thereby possible to suppress penetration of chloride ions via the pore solution in the concrete.

Expansive additives are widely used in the field of civil engineering and building to reduce drying shrinkage cracks in concrete structures. The reaction mechanism of the expansive additive actively generates $\mathrm{CH}$ or ettringite during the initial stage of hydration of the cement, thereby introducing expansion strain into the concrete. The number of cracks and crack width can be suppressed by using an expansive additive, and thereby suppress the permeation of chloride ions into the concrete via the cracks. Many performance evaluations have been reported for individual use of chloride-immobilizing materials and expansive additives as concrete additives, but there are few reports on their combined effects (ITO, 2015; 2018). This lack of data limits the use of these materials in durable designs. This study evaluated the basic performance of concretes using the chloride-immobilizing material, $\mathrm{CA}_{2}$, combined with an expansive additive, to understand the permeation behavior of the chloride ion. This is important in durability verification. Basic properties of the concretes and their salt penetration resistance were investigated. 


\section{EXPERIMENTAL}

\section{Materials}

Ordinary Portland cement (OPC) and blast furnace cement (BB; 50\% slag content) were used. $\mathrm{CA}_{2}$ was prepared to have a $\mathrm{CaO} / \mathrm{Al}_{2} \mathrm{O}_{3}$ molar ratio of 0.5 , using calcium carbonate and aluminum oxide industrial raw materials that were calcined in a rotary kiln held at $1750-1850{ }^{\circ} \mathrm{C}$. Crushed clinker obtained by gradual cooling was used for the tests. A lime-ettringite composite system was used as the expansive additive (Ex). Table 1 shows the chemical compositions and density of the concrete components. Natural sand (S) (density: $2.56 \mathrm{~g} / \mathrm{cm}^{3}$ ) from Kimitsu City, Chiba Prefecture, Japan, and coarse aggregate $(\mathrm{G})$ (density: $2.70 \mathrm{~g} / \mathrm{cm}^{3}$ ) from Oga Sesima Mountain Limestone, Japan, were used in making the concrete.

Table 1. Chemical and Physical Properties of Main Concrete Components

\begin{tabular}{|c|c|c|c|c|c|c|}
\hline \multirow{2}{*}{ Component } & \multicolumn{5}{|c|}{ Chemical composition (mass\%) } & \multirow{2}{*}{$\begin{array}{c}\text { Density } \\
\left(\mathrm{g} / \mathrm{cm}^{3}\right)\end{array}$} \\
\cline { 2 - 6 } & $\mathrm{CaO}$ & $\mathrm{SiO}_{2}$ & $\mathrm{Al}_{2} \mathrm{O}_{3}$ & $\mathrm{SO}_{3}$ & $\mathrm{Fe}_{2} \mathrm{O}_{3}$ & \\
\hline OPC & 64.1 & 20.5 & 5.2 & 2.1 & 3.0 & 3.16 \\
\hline $\mathrm{CA}_{2}$ & 24.0 & 0.6 & 67.7 & 0.01 & 7.1 & 2.96 \\
\hline $\mathrm{Ex}$ & 70.6 & 1.0 & 7.2 & 18.5 & 0.8 & 3.10 \\
\hline
\end{tabular}

\section{Standard Concrete Formula}

The amount of $\mathrm{CA}_{2}$ in the concrete formulations was held constant at $20 \mathrm{~kg} / \mathrm{m}^{3}$. Adjustment was made so that the expansion strain of the concrete at an age of 7 days was in the range of $150 \times 10^{-6}$ to $250 \times 10^{-6}$, which represents the required contraction compensation performance of concrete as specified by the Japan Society of Civil Engineers (JSCE). A preliminary test confirmed the amount of expansive additive required to obtain this predetermined expansion strain.

The standard dosage of expansive additive is usually $20 \mathrm{~kg} / \mathrm{m}^{3}$ (Ex20). Testing was also carried out with this amount increased by 10\% (Ex22) and 20\% (Ex24). The test compositions are shown in Table 2, where $\mathrm{W}$ represents the water addition. The test method was in accordance with the JIS A 6202 Japanese standard. Regarding this test, the test location was different from other test. Therefore natural sand $(\mathrm{S})$ (density: $2.62 \mathrm{~g} / \mathrm{cm}^{3}$ ) and natural coarse aggregate $(\mathrm{G})$ (density: $2.65 \mathrm{~g} / \mathrm{cm}^{3}$ ) were sourced from the Himekawa River of Niigata Prefecture, Japan were used for the test. 
Table 2. Mixture Designs of Concretes used for Expansion Tests $\left(\mathrm{kg} / \mathrm{m}^{3}\right)$

\begin{tabular}{|c|c|c|c|c|c|c|}
\hline Test No. & $\mathrm{W}$ & OPC & $\mathrm{CA}_{2}$ & Ex & $S$ & $\mathrm{G}$ \\
\hline Ex20 & \multirow{3}{*}{170} & \multirow{3}{*}{269} & \multirow{3}{*}{20} & 20 & 864 & 946 \\
\hline Ex22 & & & & 22 & 863 & 945 \\
\hline Ex24 & & & & 24 & 862 & 944 \\
\hline
\end{tabular}

\section{Evaluation of Basic Physical Properties of Concrete}

Table 3 shows the mixture designs of concretes used for evaluating basic physical properties and salt resistance. Note that the cement, $\mathrm{CA}_{2}$, and expansive additive were regarded as binders; W/B represents the water/binder ratio. Physical properties of the concrete were measured when $\mathrm{CA}_{2}$ and the expansive additive were both individually included and used together. For comparison, tests were also conducted on concrete made using BB.

The basic physical properties of slump and air content were measured according to JIS A 5308 to confirm the fresh properties of the concrete. For physical testing, the compressive strength at 28 days of aging was measured according to JIS A 1108. Regarding the formulation using the expansion material, the 7-day expansion was measured using the JCI-S-009-2012 standard of the Japan Concrete Engineering Society.

Table 3. Mixture Designs of Concretes used for Chloride-Penetration Resistance

\begin{tabular}{|c|c|c|c|c|c|c|c|c|c|}
\hline Test & $\mathrm{W} / \mathrm{B}$ & S/a & Air & \multicolumn{6}{|c|}{ Unit weight $\left(\mathrm{kg} / \mathrm{m}^{3}\right)$} \\
\hline No. & $(\%)$ & $(\%)$ & $(\%)$ & W & OPC & $\mathrm{CA}_{2}$ & Ex & $S$ & $\mathrm{G}$ \\
\hline $\mathrm{N}$ & \multirow{5}{*}{55} & \multirow{6}{*}{48} & \multirow{6}{*}{$4.5 \pm 1.5$} & \multirow{6}{*}{170} & 309 & - & - & 864 & 965 \\
\hline BB & & & & & 310 & & & 859 & 959 \\
\hline $\mathrm{NC}$ & & & & & 289 & 20 & - & \multirow{3}{*}{864} & \multirow{3}{*}{964} \\
\hline $\mathrm{NE}$ & & & & & 287 & - & 22 & & \\
\hline NCE55 & & & & & 267 & 20 & 22 & & \\
\hline NCE45 & 45 & & & & 336 & 20 & 22 & 836 & 934 \\
\hline
\end{tabular}

\section{Evaluation of Salt Penetration Resistance}

The evaluation of the salt penetration resistance of concrete was carried out using two methods: the salt-water immersion test and the unsteady-state electrophoresis test.

In the salt-water immersion test, a prism specimen $(10 \mathrm{~cm} \times 10 \mathrm{~cm} \times 40 \mathrm{~cm})$ was 
cured in water at $20^{\circ} \mathrm{C}$ for up to 28 days of age. Five of the six faces were then coated with epoxy resin, leaving one side of $10 \mathrm{~cm} \times 40 \mathrm{~cm}$ exposed. The prism was immersed in $10 \% \mathrm{NaCl}$ aqueous solution at $20{ }^{\circ} \mathrm{C}$. The specimens were then sequentially split at predetermined ages and a silver nitrate solution $(0.1 \mathrm{~mol} / \mathrm{L})$ sprayed on the cleaved surface. This reacted with chloride to give a whitebcolor. The depth from the exposed surface to the colored portion was measured.

The unsteady-state electrophoresis test was conducted to compare the diffusion coefficients of chloride ions in each concrete formulation. A conventional electrophoresis test apparatus, was used. Specimens were prepared using cylindrical molds made of vinyl chloride (diameter: $100 \mathrm{~mm}$; height: $50 \mathrm{~mm}$ ). The specimens were subjected to vacuum-saturation pretreatment using saturated calcium hydroxide. Aqueous $\mathrm{NaOH}(0.3 \mathrm{~mol} / \mathrm{L})$ was injected to the anode side of the test apparatus and $\mathrm{NaCl}$ solution (3\%) to the cathode side. The applied voltage was kept constant at 30 $\mathrm{V}$ and current was passed. Once energization was completed, the specimen was removed and split. The chloride ion penetration depth was measured by spraying the exposed surface with silver nitrate solution $(0.1 \mathrm{~mol} / \mathrm{L})$.

\section{RESULTS AND DISCUSSION}

\section{Setting the Standard Formula}

Figure 2 shows the change of length of the fresh concrete in preliminary tests. The expansion strain increased with increasing amount of expansive additive. When using the expansive additive alone at a concentration of $20 \mathrm{~kg} / \mathrm{m}^{3}$, the expansion strain reached about $200 \times 10^{-6}$ (Hori, 2005), whereas its combination with $\mathrm{CA}_{2}$ showed a tendency to decrease this strain. This is attributed to the consumption of $\mathrm{CH}$, which is the source of expansion strain, by reaction with $\mathrm{CA}_{2}$, which is converted to $\mathrm{HC}$ and does not contribute to the introduction of expansion strain (Ito, S., 2015; Ito, T., 2015). When the concentration of the expansive additive was set to $22 \mathrm{~kg} / \mathrm{m}^{3}$ (10\% more than usual), the expansion strain fell within the JSCE-specified range. 


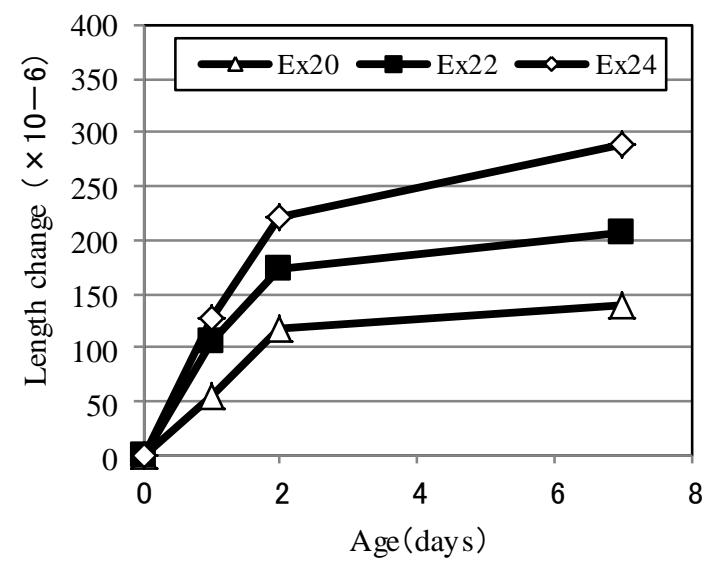

Fig. 2. Results of preliminary concrete expansion tests

The objective of this test was to evaluate the properties of concretes combining chloride immobilization by $\mathrm{CA}_{2}$ after introducing a predetermined expansion strain, so the amount of expansive additive added in subsequent tests was $22 \mathrm{~kg} / \mathrm{m}^{3}$ (Table 3 ). These results suggested that it is necessary to confirm the optimum addition of expansion addition required to achieve a predetermined expansion strain by a preliminary test when used in combination with $\mathrm{CA}_{2}$.

\section{Physical Properties of Fresh Concrete}

Table 4 shows the fresh properties of various formulations at a W/B of $55 \%$. Addition of the expansive additive water-reducing agent was kept constant, but slight slump was measured for the NC and NE formulations. Although it has been reported that slump slightly decreases due to the addition of $\mathrm{CA}_{2}$, the cause is unknown because the expansive additive had almost no influence on the slump or air volume. This is an adjustable parameter that depends on the addition rate of the admixtures; it is considered that the influence on handling is small. In this test, NCE55 was equivalent to the $\mathrm{N}$ and $\mathrm{BB}$ formulations, and no influence on fresh properties of the $\mathrm{CA}_{2}$ and expansive additive combination was observed.

Table 4. Physical Properties of Fresh Concretes

\begin{tabular}{|c|c|c|c|c|c|}
\hline Property & N & BB & NC & NE & NCE55 \\
\hline Slump $(\mathrm{cm})$ & 17.5 & 18.0 & 13.0 & 14.5 & 18.5 \\
\hline Air $(\%)$ & 4.8 & 4.0 & 4.9 & 3.9 & 5.0 \\
\hline
\end{tabular}




\section{Strength Properties}

Figure 3 shows the results of compressive strength measurements at 28 days of age. It shows the average value of the three specimens. Compressive strength was about $10 \%$ higher in NC, NE, and NCE55 compared with that of $\mathrm{N}$ and BB. NC compounded with $\mathrm{CA}_{2}$ and NCE55 are considered to have increased strength due to the addition of $\mathrm{CA}_{2}$ because the air volume was very similar for $\mathrm{N}$ and $\mathrm{BB}$. It was inferred that densification of the paste portion contributed to the increase in strength because the number of pores in a hardened paste is reduced by addition of $\mathrm{CA}_{2}$ (Ito, S., 2015). Addition of $\mathrm{CA}_{2}$ or its admixture with the expansive additive did not adversely affect the strength, and there was no problem with the combined use of both.

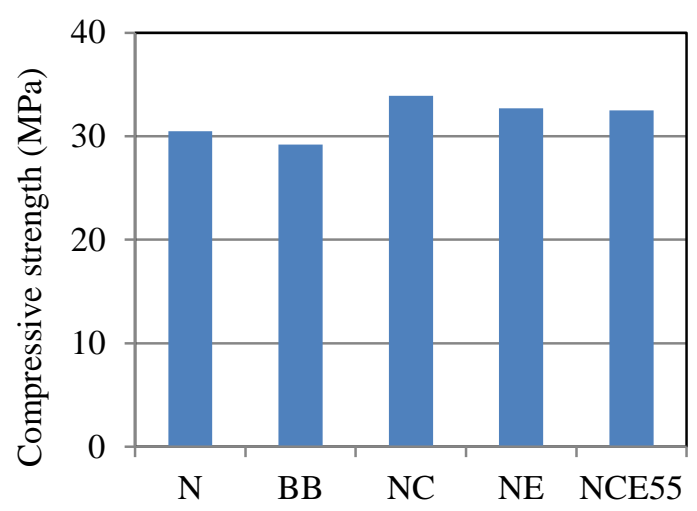

Fig. 3. Compressive strength results

\section{Expansion Characteristics}

Figure 4 shows the results of the measurement of expansion strain at 7 days of age for NE, NCE55 (blended with expansive additive), and NCE45 (which contained a different W/B). In NCE55, the expansion strain at 7 days of age was $211 \times 10^{-6}$, which is equivalent to the value determined in the preliminary test, so an expansion strain satisfying the criteria proposed by JSCE was obtained. In addition, NCE45 showed the same expansion and no influence of the W/B was observed. In the case of NE, in which the same amount of expansion material was added alone, the expansion strain at 7 days of age was $245 \times 10^{-6}$, confirming that this strain decreased by about $15 \%$ when combined with $\mathrm{CA}_{2}$. A previous study reported that the amount of $\mathrm{CH}$ in the cement paste decreased when it was used in combination with $\mathrm{CA}_{2}$ compared with the expansive additive alone. It was therefore inferred that a similar reaction occurred in this test, leading to a decrease in the expansion strain. 


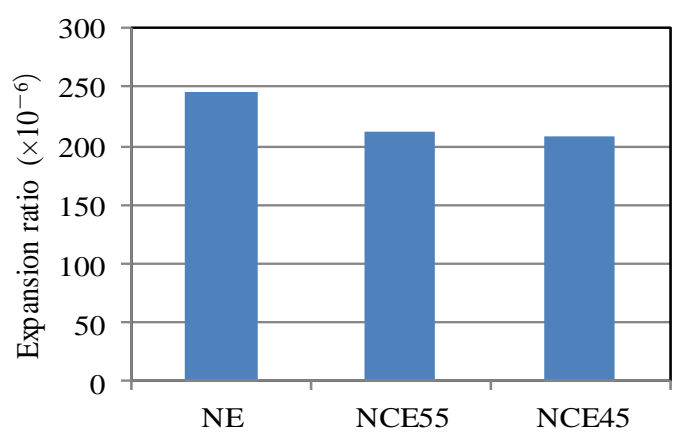

Fig. 4. Results of expansion test

\section{Salt Immersion Test}

Figure 5 shows the chloride-ion penetration depth of concrete specimens immersed in $10 \% \mathrm{NaCl}$ solution. The penetration depth of the reference $\mathrm{N}$ formulation after 8 weeks of immersion was about $10 \mathrm{~mm}$, whereas that of the NC and NCE55 specimens was about $6 \mathrm{~mm}$. Penetration of chloride ions was suppressed by the addition of $\mathrm{CA}_{2}$. The difference between these specimens and the comparative $\mathrm{BB}$ was about $1 \mathrm{~mm}$, and no significant difference was found in penetration depth as evaluated for this immersion period.

It is presumed that $\mathrm{HC}$ generated by addition of $\mathrm{CA}_{2}$ immobilized the chloride ion as Friedel's salt and inhibited penetration into the concrete interior. The penetration depth of chloride ion was low for all samples for the immersion time of 8 weeks, so future evaluation will be carried out for a longer period and by comparison of penetration depth with the diffusion coefficient. The chloride penetration depth was hardly affected, even when used in combination with the expansive additive. Considering that the expansion strain fell within the range conforming to the specified criteria, there was almost no influence on chloride ion penetration, i.e., as long as the correct range of expansion strain was satisfied, there were no problems with combining $\mathrm{CA}_{2}$ and the expansive additive. It is expected that both crack resistance and the penetration-suppressing effect on the chloride ion are compatible. 


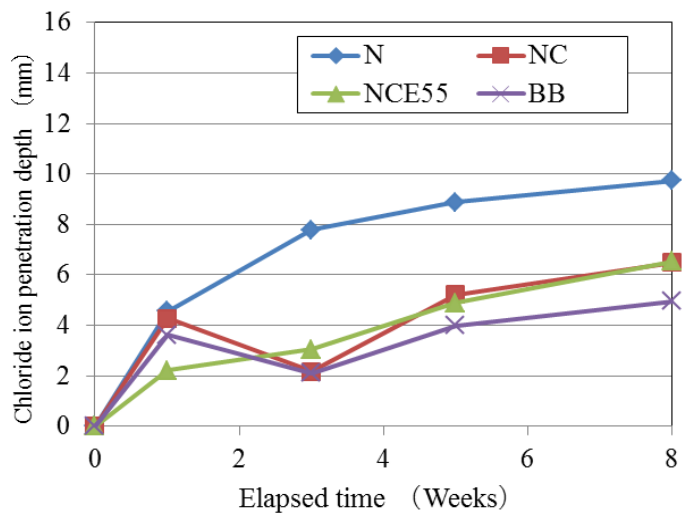

Fig. 5. Chloride-ion penetration depth as measured by the salt-water immersion test

\section{Unsteady-State Electrophoresis Test}

With reference to a previous study (Iyoda, 2014), unsteady-state electrophoresis tests were conducted to evaluate the diffusion rate of chloride ions into concrete. Figure 6 shows the relationship between energization time and chloride-ion penetration depth. Figure 7 shows the diffusion coefficients calculated using Equation 3 (Nordtest, 1999), using the penetration depth after 24 h energization:

$$
D_{n s s m}=\frac{0.0239(273+T) L}{(U-2) t}\left(X_{d}-0.0238 \sqrt{\frac{(273+T) L X_{d}}{U-2}}\right),
$$

where $D_{n s s m}$ is the diffusion coefficient $\left(\times 10^{-12} \mathrm{~m}^{2} / \mathrm{s}\right), U$ is the applied voltage (V), $T$ is the temperature $\left({ }^{\circ} \mathrm{C}\right), L$ is the specimen thickness $(\mathrm{mm}), X_{d}$ is the chloride-ion penetration depth (mm), and $t$ is the test duration (h).

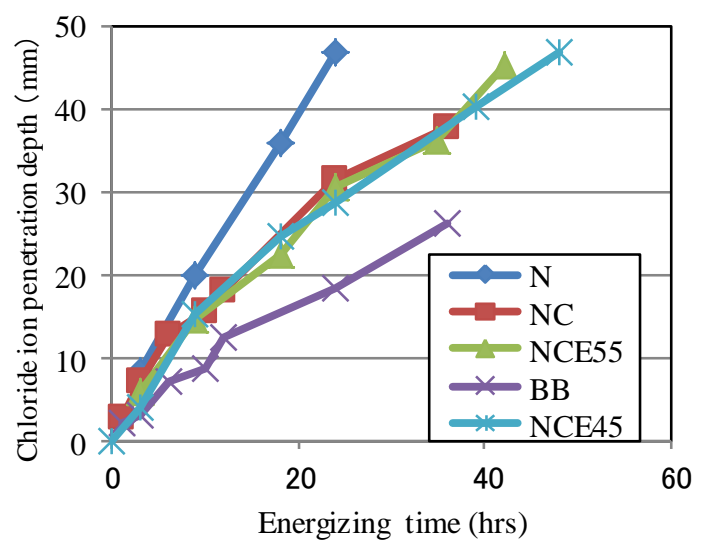

Fig. 6. Chloride-ion penetration depth as measured by the unsteady-state electrophoresis test 


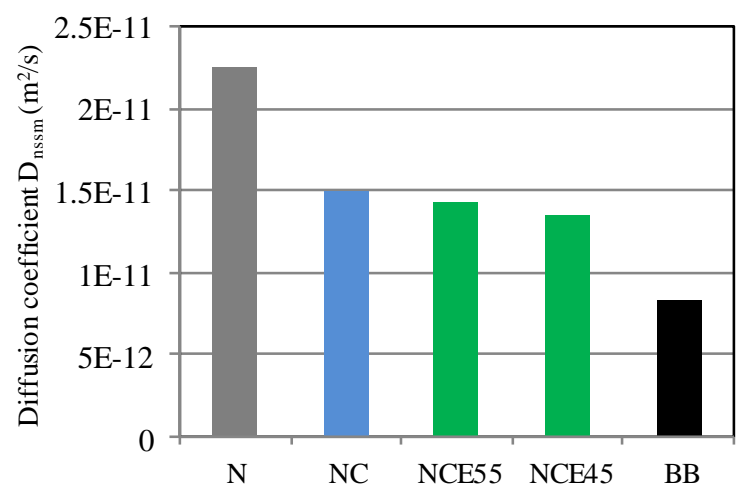

Fig. 7 Diffusion coefficients for different concrete formulations as measured by the unsteady-state electrophoresis test

The penetration depth of the chloride ion for the same current application time was largest in the $\mathrm{N}$ specimen, followed by NC, NCE55, and BB. Chloride-ion penetration was suppressed in the NC and NCE55 specimens compared with N, due to a reduction in the diffusion coefficient of about 30 to $40 \%$ (Fig. 7). Because NC and NCE55 showed similar behavior, the ability to immobilize chloride ions depended on the addition of $\mathrm{CA}_{2}$ in both formulations. This suggested that, even when combined with expansive additives and within the range of the expansion coefficient, the addition of $\mathrm{CA}_{2}$ does not have a negative effect. In contrast, NCE45 (with a low W/B) had the same diffusion coefficient as the NCE55 formulation.

The difference in penetration depth of the chloride ion in the salt-water immersion test for up to 8 weeks was about 1 to $2 \mathrm{~mm}$, whereas the diffusion coefficient was 1.5 to 2 times larger: the results differed greatly depending on the test method. Considering that the void structure of the cured body may be responsible for this effect, the porosities of specimens that had been subjected to the unsteady-state electrophoresis test were measured by mercury intrusion porosimetry using an Auto Pore IV 9500 (Micromeritics, USA). Figure 8 shows representative results of the cumulative pore volumes before and after energization for the $\mathrm{NC}$ and $\mathrm{BB}$ specimens with $\mathrm{CA}_{2}$ added. The number of pores decreased after energization, particularly those of about $0.1 \mu \mathrm{m}$ in size, but there was no significant difference between the two specimens. Conversely, if fine voids of $0.01 \mu \mathrm{m}$ or less were included, the cumulative void volume was larger in the BB specimen. 


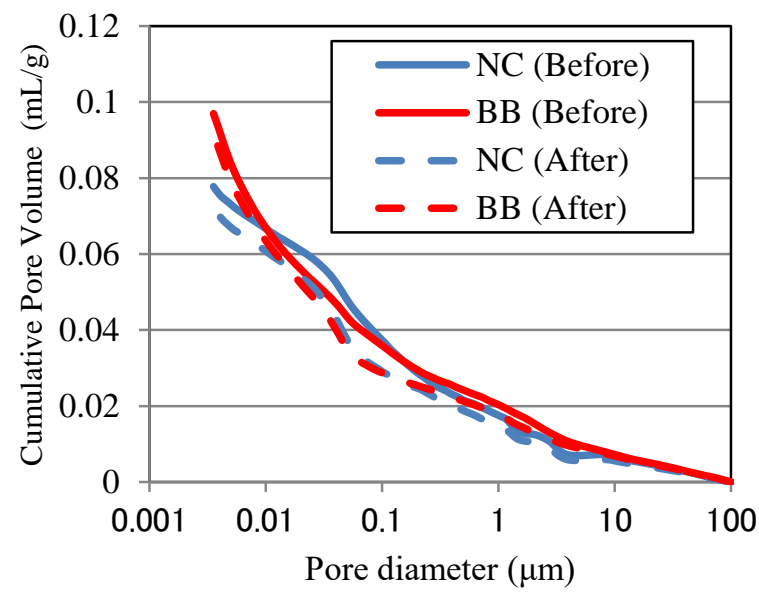

Fig. 8 Pore volumes of selected concrete specimens before and after energization in unsteady-state electrophoresis test

No relationship between the void volume and the penetration depth and diffusion coefficient of the chloride ion obtained by unsteady-state electrophoresis could be identified. The difference between the results of the salt-water immersion and unsteady-state electrophoresis tests is considered not directly attributable to the void structure inside the cured body.

A previous study classified chloride ions entering the cured body as either chemically adsorbed ions immobilized in the hydrate as Friedel's salt or as physisorbed ions that are immobilized by physical forces, such those of electrostatic attraction and van der Waals forces on the surface of the pore wall. $\mathrm{CA}_{2}$ and the blast furnace slag have different mechanisms of immobilization of chloride ions, so they may exhibit different migration behaviors under energized environments, such as the unsteady-state electrophoresis test. Further examination of changes in hydrates and the influence of test conditions is required.

\section{SUMMARY}

The results of this research are summarized as follows:

(1) Concrete formulations in which $\mathrm{CA}_{2}$ was combined with an expansive additive showed a tendency to decrease the expansion strain. This was attributed to the consumption of $\mathrm{CH}$, which is the source of strain, by the reaction of $\mathrm{CA}_{2}$ and its conversion to $\mathrm{HC}$, which does not contribute to the introduction of expansion strain. 
(2) The compressive strength of a blended mixture of $\mathrm{CA}_{2}$ was equal to or higher than that of the formulation without $\mathrm{CA}_{2}$. Provided the concrete behavior fell within the range of an appropriate expansion ratio, there was no influence on the compressive strength due to the combined use of $\mathrm{CA}_{2}$ and the expansive additive

(3) In the salt-water immersion test, the penetration depth of the chloride ion was smaller than that of ordinary cement. The penetration-suppressing effect of the combination of $\mathrm{CA}_{2}$ and the expansive additive was confirmed.

(4) In the salt-water immersion test, the combined use of $\mathrm{CA}_{2}$ and expansive additive had almost no influence on salt tolerance, provided that the expansion strain was within the appropriate range.

(5) Results of the unsteady-state electrophoresis test indicated that the diffusion coefficient of the chloride ion in concrete mixed with $\mathrm{CA}_{2}$ was smaller by 30 to $40 \%$ than that in the concrete without $\mathrm{CA}_{2}$.

(6) The penetration behaviors of chloride ions differed in concrete mixed with $\mathrm{CA}_{2}$ in the saline immersion and unsteady-state electrophoresis tests. This is not attributed to the void structure of the cured body, but to the differing movement characteristics of ions under energized environments due to their chloride-ion immobilization mechanisms.

\section{ACKNOWLEDGEMENTS}

We thank Kathryn Sole, PhD, from Edanz Group (www.edanzediting.com/ac) for editing a draft of this manuscript.

\section{REFERENCES}

Ito, S. (2015). "Evaluation of salt resistance of low heat Portland cement using chloride ion immobilized material and expansive additive." Cem. Sci. Concr. Technol., 69, 221-227.

Ito, S. (2018). "Evaluation of salt resistance of concrete using chloride ion immobilized material and expansive additive." Proceedings of the Japan Concrete Institute, vol.40, 729-734.

Hori, A. (2005). "Study of salt resistance of concrete using low dosage type expansive additive." Proceedings of the Japan Concrete Institute, vol.27, $679-684$. 
Ito, T. (2015). "Study on effect of prevention for chloride ion using both of $\mathrm{CA}_{2}$ and expansive additive to low heat Portland cement." $69^{\text {th }}$ Annual meeting of cement and concrete engineering, pp. 236-237.

Iyoda, T. (2014). "Evaluation for curing effect on blast furnace slag concrete by unsteady-state electrophoresis test." Cem. Sci. Concr. Technol., 68, 275-282.

Morioka, M. (2005). “Cement additive and cement composition.” JP2005-104828.

NordTest (1999). "Chloride migration coefficient from non-steady state migration experiment". NT BUILD 492, Espoo, Finland.

Tabara, K. (2010). "Fixation ability of chloride ion by hardened cement added with $\mathrm{CaO} \cdot 2 \mathrm{Al}_{2} \mathrm{O}_{3}$." Cem. Sci. Concr. Technol., 64, 428-434.

Tabara, K. (2011). "Hydration behavior and fixation ability of chloride ion by a variety of kinds of hardened cements added with $\mathrm{CaO} \cdot 2 \mathrm{Al}_{2} \mathrm{O}_{3}$." Cem. Sci. Concr. Technol, 65, 427-434. 